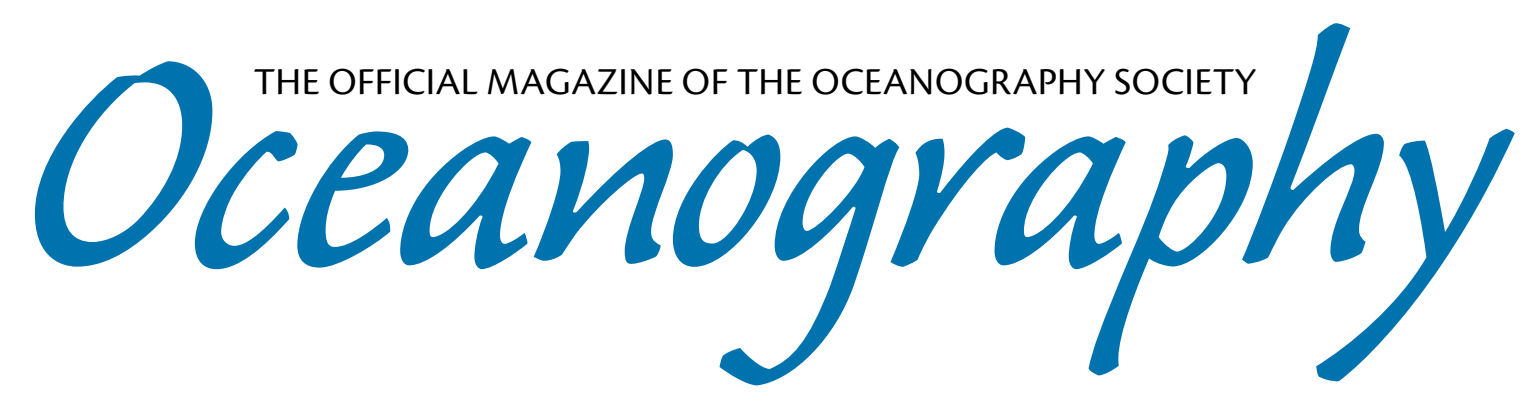

CITATION

Rowley, C., and A. Mask. 2014. Regional and coastal prediction with the Relocatable

Ocean Nowcast/Forecast System. Oceanography 27(3):44-55, http://dx.doi.org/10.5670/

oceanog.2014.67.

DOI

http://dx.doi.org/10.5670/oceanog.2014.67

COPYRIGHT

This article has been published in Oceanography, Volume 27, Number 3, a quarterly journal of The Oceanography Society. Copyright 2014 by The Oceanography Society. All rights reserved.

USAGE

Permission is granted to copy this article for use in teaching and research. Republication, systematic reproduction, or collective redistribution of any portion of this article by photocopy machine, reposting, or other means is permitted only with the approval of The Oceanography Society. Send all correspondence to: info@tos.org or The Oceanography Society, PO Box 1931, Rockville, MD 20849-1931, USA. 


\section{Regional and Coastal Prediction with the Relocatable Ocean Nowcast/Forecast System}

BY CLARK ROWLEY AND ANDREA MASK

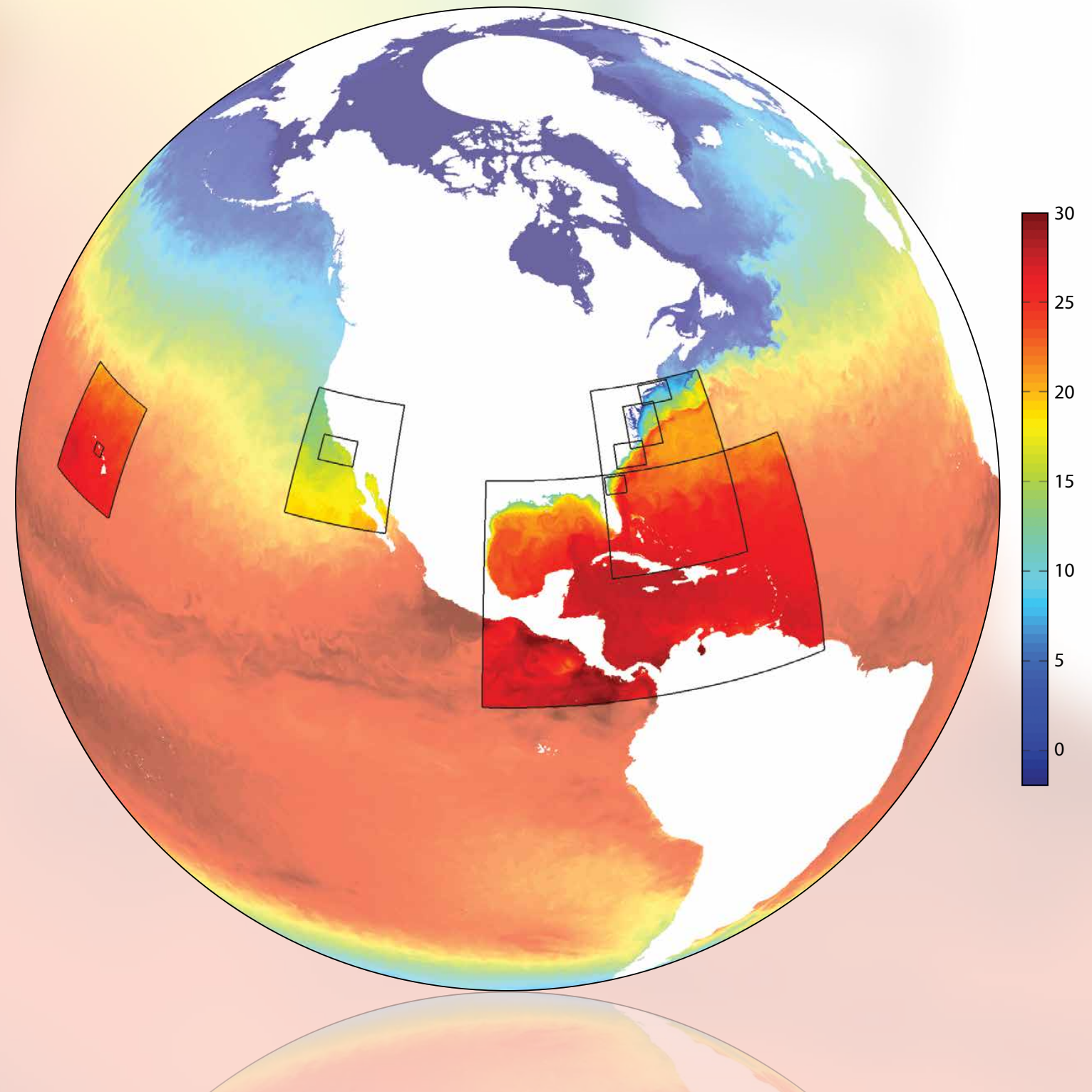


ABSTRACT. The US Navy maintains a capability for regional and coastal ocean modeling as part of a comprehensive effort to predict the impact of the environment (air, water, land, and ice) on naval operations, training, and support activities. The current operational regional ocean modeling capability is based on the Naval Research Laboratory's RELOcatable ocean nowcast/forecast (RELO) system, and this system has formed the basis for further development in advanced data assimilation, ensemble prediction, and coupled modeling. This article presents an overview of the RELO system and its operational application.

\section{INTRODUCTION}

The Naval Research Laboratory (NRL) RELOcatable ocean nowcast/forecast system (RELO), based on the Navy Coastal Ocean Model (NCOM) and the Navy Coupled Ocean Data Assimilation (NCODA) system, provides a capability for relocatable ocean forecast modeling and data assimilation that is used for operational forecast support for antisubmarine warfare; intelligence, surveillance, and reconnaissance; Navy special operations; and other applications. The RELO system produces nowcasts and forecasts of three-dimensional (3D) ocean temperature, salinity and current structures, the surface mixed layer, the location of mesoscale features such as eddies, meandering currents and fronts, and the generation and propagation of external and internal tides. The RELO system is implemented in areas where US Navy exercises or operations are anticipated, including most of the US coast (Figure 1).

Operational ocean modeling for the US Navy is performed primarily at the Naval Oceanographic Office (NAVOCEANO) in Stennis Space Center, Mississippi. Prior to 2008, regional and coastal modeling at NAVOCEANO was performed using the Shallow Water Analysis and Forecast System (SWAFS; Horton et al., 1997), a combined ocean assimilation and forecast system in development since the early 1990s. In 2008, NAVOCEANO deployed and assessed implementations of the RELO system during exercises and operations in the western North Pacific and around Hawaii. The RELO system was found to offer equivalent or better sound-speed forecast skill than SWAFS, with a system both easier to maintain and offering an expanded upgrade path. RELO was also found to provide higher horizontal and vertical resolution than could be implemented with the existing NCOM global forecast system, the assimilation of more data sources than were used in the global system, and representation of external and internal tides. In some regions, including several of particular US Navy interest, the
OPPOSITE PAGE | Figure 1. RELO (RELOcatable ocean nowcast/forecast system) domains covering US coastal areas. The background field is the surface temperature from the global HYCOM nowcast for $00 \mathrm{Z}$ January 15,2014 . The inset fields with black outlines display the $00 Z$ January 15,2014 , surface temperatures from the 10 RELO domains adjacent to the US continental and Hawaii coasts. internal tide is an important contributor to the variability and complexity of the subsurface ocean structure on time scales of hours to days.

Since its introduction, the RELO system has been adapted to meet new operational capabilities. Today, high-resolution regional implementations of NCOM at NAVOCEANO complement the global ocean sound-speed forecast capability of the Global Ocean Forecast System (GOFS). The global $1 / 12^{\circ}$ implementation of the HYbrid Coordinate Ocean Model (HYCOM), the forecast model component of GOFS, provides the open boundary information needed for NCOM nests. The RELO system uses a 3D Variational (3DVAR) version of NCODA, and the analysis software is regularly updated to assimilate new satellite and in situ data sources.

The primary challenge to ocean forecast modeling with relatively high resolution at regional scales is the disparity between the horizontal scales represented in the ocean model configured with $3 \mathrm{~km}$ resolution (expected to resolve features of $\sim 15 \mathrm{~km}$ with five grid points) and those that may be resolved with a suite of satellite altimeters when several are present and operational $(\sim 100 \mathrm{~km})$. The altimeter data provide an integral measurement of the water column that requires additional methods to project their influence below the surface, but these data are the best available source for constraining the subsurface thermohaline structure in the open ocean. Profile data, though extremely valuable, are usually too sparse to constrain an ocean model in real 
time. This disparity in represented scales makes the data assimilation problem more challenging because it is difficult to appropriately match the resolutions of model and observation to properly correct the model forecast state.

Coastal and nearshore domains pose distinct challenges due to the shorter length and time scales of dynamics arising from, for example, interaction its implementation at NAVOCEANO, and current developments in modeling and data assimilation.

\section{THE RELO SYSTEM}

The RELO system consists of a forecast model component appropriate for regional- to coastal-scale ocean modeling, a data analysis component, and supporting codes, scripts, and

THE RELO SYSTEM CONSISTS OF A FORECAST MODEL COMPONENT APPROPRIATE FOR REGIONALTO COASTAL-SCALE OCEAN MODELING, A DATA ANALYSIS COMPONENT, AND SUPPORTING CODES, SCRIPTS, AND DATABASES FOR DOMAIN CONFIGURATION, DATA PREPARATION, DATA ASSIMILATION, AND POST-PROCESSING.

with coastline geometry and nearshore bathymetry, freshwater forcing, topographically influenced wind forcing, or wave-current interactions. There is a similar lack of dense observations sufficient to constrain the model, which may demand resolution finer than $100 \mathrm{~m}$ to properly represent these dynamics. Some of these circulation features are associated with the local coastline and are less subject to stochastic variability from downscaling in the ocean model, and are less dependent on boundary conditions from a larger-scale regional or global model; therefore, in some cases the forecast skill will depend strongly on model configuration as well as on data assimilation (e.g., De Mey et al., 2009).

This article describes the current state of the operational RELO forecast system, databases for domain configuration, data preparation, data assimilation, and post-processing. The system configures cycling analysis-forecast systems for limited-area models in which the analysis and forecast are performed at the same resolution.

Each regular daily cycle of the system is organized around four tasks. First, an analysis is conducted to assimilate newly available observations into the previous forecast model output. Second, an update incorporates the new analysis into the forecast model state for the valid time of the analysis (the nowcast). This is typically performed either gradually, during a brief hindcast simulation, or by simply inserting the analysis into the model state. Third, using the updated nowcast as the initial condition, a model forecast is generated and extended out to a defined forecast period, which is usually limited by the availability of forecast winds and fluxes from an atmospheric model. Finally, the forecast output is post-processed into products for the customer in the form of netCDF files suitable for further processing at NAVOCEANO.

The system is designed so that a single installation of codes and scripts supports multiple users (e.g., a mix of operational and research users). In addition, all RELO forecast domains use the same installed software, so that multiple instances of model codes or scripts do not need to be individually maintained. This is an important characteristic for a system at an operational center.

NCODA: Data Analysis

\section{Component}

The Navy Coupled Ocean Data

Assimilation system is the data analysis component (Cummings and Smedstad, 2013). NCODA is in operational use at both Navy production centers, the Fleet Numerical Meteorology and Oceanography Center (FNMOC) and NAVOCEANO, as a stand-alone cycling analysis system, performing 2D ocean surface temperature and ice concentration and 3D temperature and salinity analyses that together provide background fields for the quality control of ocean observations. In addition, the 2D analyses are used to provide lower boundary conditions of sea surface temperature and ice concentration for atmospheric models at both centers (global and regional models at FNMOC, regional models at NAVOCEANO). NCODA also runs in a cycling mode with forecast models, and is the analysis component for the operational GOFS system at NAVOCEANO. 
The observational data used for assimilation include satellite sea surface temperature (SST), satellite altimeter sea surface height anomaly (SSHA), satellite microwave-derived sea ice concentration, and in situ surface and profile data from sensors on ships; drifters; fixed buoys; profiling floats; expendable bathythermographs (XBTs); conductivity, temperature, depth sensors (CTDs); gliders; and marine mammals. The observational data are prepared and processed through the NCODA automated data quality control system, which associates each observation with a probability of error compared against climatological or model fields with related variability information. The operational data feeds at NAVOCEANO include multiple sources of polar orbiting and geostationary infrared and microwave satellite SST, all available SSHAs, public sources of in situ observations (e.g., ships, drifters, XBTs) from the Global Telecommunication System, restricted in situ observations from NAVOCEANO survey ships and autonomous vehicles, and, for some regions, classified in situ observations from US Navy ships.

In much of the ocean, SSHA measurements may be used to infer subsurface density structure. SSH reflects not only the horizontal density variation but also other processes (e.g., atmospheric pressure and wind-driven circulation); thus, SSHA measurements are most successful in deep water, off the continental shelf, where the SSHA from the long-term mean is well correlated with the density variation and relatively less influenced by the other processes. Methods to infer the density variation include using simple one-layer reduced gravity models to relate SSHA to an isopycnal displacement (Mainelli et al., 2008) or linear regression between SSHA and subsurface parameters (Fox et al., 2002; Willis et al., 2003). Given the relative abundance of altimetric observations compared with in situ profile observations, SSHA is an important source of information about the ocean subsurface.

In the present RELO system, NCODA assimilates SSHA into the subsurface ocean through the generation of synthetic profiles of temperature and salinity based on the SST and SSHA. Fox et al. (2002) describe the methodology for generating the synthetic profiles, which is based on a climatological database of subsurface temperature anomalies regressed against SSHA and SST. The synthetics here are generated along altimeter tracks. Because the in situ observing system of buoys, drifters, and floats is not sufficient to observe the mesoscale eddy field, availability of altimeter data is key to maintaining the fidelity of the real-time system. A recent advance in SSHA assimilation in Navy models is the Improved Ocean Synthetic Profile (ISOP) technique, now being tested in cycling assimilation systems with NCODA. The ISOP technique improves on Fox et al. (2002) by using a three-layer approach to better account for the surface mixed layer, vertical gradients between the mixed layer and the thermocline, and the quiescent deep ocean, leading to a better overall representation of vertical gradients. The ISOP technique also uses the forecast model profile in forming the synthetic profile and better maintains the influence of previously assimilated profile observations with a less "climatelike" synthetic profile.

Clark Rowley (clark.rowley@nrlssc.navy.mil) is Oceanographer, Naval Research Laboratory, Oceanography Division, Stennis Space Center, MS, USA. Andrea Mask is Ocean Forecasting Branch Head and Regional Modeling Lead, Naval Oceanographic Office, Stennis Space Center, MS, USA.
The regional NCODA analysis uses the forecasts from the regional NCOM model as the background in a 3DVAR analysis of temperature, salinity, dynamic height (geopotential), and the $\mathrm{u}, \mathrm{v}$ components of vector velocity (Cummings and Smedstad, 2013). The NCODA 3DVAR analyzes all variables simultaneously. Horizontal covariances that are multivariate between geopotential and velocity produce updates to the model mass and velocity fields that are in geostrophic balance. Changes in geopotential are in hydrostatic agreement with computed changes in the temperature and salinity fields. Time series of 3D NCOM temperature, salinity, and velocity forecast fields provide the background for the analysis. Corrections to the background fields computed by NCODA are used to update the model state, resulting in model initial conditions that are consistent with the most recent observations. There is no direct communication between the global and regional NCODA analyses.

In the RELO system, NCODA is normally configured to use Rossby radius-dependent covariance length scales also scaled by the horizontal grid spacing, and vertical correlation length scales determined using the vertical gradient of the climatological mean density. This procedure results in short length scales in the thermocline and longer length scales near the surface and in the deep ocean. The analyses in RELO use the first-guess-at-appropriate-time (FGAT) method (Fisher and Andersson, 2001) to calculate observationbackground differences: observations 
for SST and subsurface temperature and salinity are matched with the hourly or three-hourly model forecast fields nearest in time. This approach alleviates some error in standard 3DVAR due to temporal variation; for example, profile observations are matched against the model fields that represent the appropriate phase of a forecast internal tide rather than against a single background field at the analysis time, which may be at a different phase from the observation.

Although the NCODA analysis does not account for correlated error in observations, there is evidence that repeated assimilation of the same SSHA observations in a series of daily GOFS analyses improves the forecast skill for the mesoscale field, particularly when fewer altimeters are operating. RELO implementations with similar large data windows (i.e., the time period used to select observations for each analysis) have also improved skill in predicting surface drifter tracks (Gregg Jacobs, Naval Research Laboratory, pers. comm., 2014). An updated data window is being actively investigated for operational implementation in the near future for both SSHA and in situ profile measurements. In addition, the current operational GOFS analysis uses a fixed profile data window of 12 days, while the RELO system assimilates only the observations received in the $24 \mathrm{~h}$ since the previous analysis.

\section{NCOM: Forecast Component}

The Navy Coastal Ocean Model is a primitive-equation model developed at NRL for local, regional, and global forecasting of temperature, salinity, sound speed, and currents. NCOM has a free surface and can represent wind- and tide-driven sea level changes (Barron et al., 2006). The NCOM configuration within the forecast system is generally flexible, with most model configuration parameters available for user definition. Default values are available to simplify model setup, so most domains can be defined with limited user input (e.g., using just the definition of the latitude-longitude box, nominal horizontal resolution, and start date). In practice, the best results will be obtained by experienced users performing domain-specific customization of, for example, bathymetry, grid specification, river placement, and model parameters.

The vertical grid structure for the forecast model is a stretched profile defined by user-specified parameters for each domain; the vertical grid levels are divided into a number of terrainfollowing sigma levels from the surface down to a specified depth, with a number of z-levels below. In the z-level portion of the grid, the terrain may be clipped to the model z-levels or represented using so-called partial cells. In regions shallower than the specified sigma-z interface, the sigma levels are terrain following. The NCODA analysis is performed on a z-level grid, which matches the vertical grid structure for the forecast model (specifically, the depths of the NCOM vertical levels as defined at the deepest grid point of the domain).

The RELO system configures the analysis and forecast components on the same horizontal grid using the set of standard projection types supported in NCODA, including unprojected (i.e., defined with regular spacing in longitude and latitude), Mercator, and Lambert Conformal grids. NAVOCEANO operations use the unprojected grids, with horizontal grid cell dimensions calculated as on a spherical Earth.

For operational implementations, surface boundary conditions for NCOM are prepared from forecast output of implementations of the Coupled Ocean Atmosphere Mesoscale Prediction System (COAMPS; Hodur et al., 2002) produced at FNMOC or NAVOCEANO. The COAMPS output fields from FNMOC are transferred to NAVOCEANO where they are locally accessible to regional ocean and wave models. Surface fields may also be prepared from output of the NAVy Global Environmental Model (NAVGEM; Hogan et al., 2014, in this issue), archived databases, or independent of the RELO system. In most operational domains, COAMPS output fields are transferred to NAVOCEANO in compressed GRIdded Binary (GRIB) format and prepared at runtime by the RELO system. The basic seven fields processed are: sea level pressure, $2 \mathrm{~m}$ air temperature and dew point depression, surface net downwelling longwave and shortwave radiation, and vector surface wind components; for some regions, total precipitation is included to add evaporation and precipitation fluxes. The momentum flux is calculated using a speed-dependent drag coefficient that extends the Large and Pond (1981) formulation to a speed of $35 \mathrm{~m} \mathrm{~s}^{-1}$, and then reduces the coefficient growth rate at higher speeds. Temperature and salinity fluxes are estimated in NCOM using bulk formulas described in Kara et al. (2005).

The limited-area models in the RELO system require ocean state information along the open lateral boundary. Regional implementations are nested in the GOFS system at NAVOCEANO, which uses a global $1 / 12^{\circ}$ implementation of HYCOM (Metzger et al., 2014, in this issue). Boundary data for the NCOM nest are extracted from the GOFS output of surface elevation, temperature, salinity, 
and currents at the available three-hourly interval. The RELO software also supports the configuration of telescoping NCOM-within-NCOM domains; for example, a $1 \mathrm{~km}$ coastal NCOM domain may be configured to use a larger $3 \mathrm{~km}$ regional NCOM domain for lateral boundary data. A Flather-type boundary condition is applied for the surface elevation and the vertically averaged transport normal to the boundary. Along-boundary currents and tracers are modeled with an Orlanski-type radiation condition. The normal velocity uses an advective condition.

\section{Model Updating}

The RELO system supports several methods to introduce corrections produced by the NCODA analyses into the NCOM forecast model, but operational systems use an incremental method in which the temperature, salinity, and (optionally) horizontal vector velocity correction fields are added gradually to the NCOM model fields during a hindcast period so that the corrections are fully integrated at the nowcast time (Bloom et al., 1996). Originally, RELO configurations used a version of NCOM that supported the addition of temperature and salinity corrections only, and they cycled with a previous form of the NCODA analysis that performed multivariate optimal interpolation.

Those configurations ran a $24 \mathrm{~h}$ hindcast period to allow the model velocities to adjust to the changes in density from the corrections without generating spurious gravity waves due to imbalances in the mass and velocity fields. The most recent versions of NCOM allow for insertion of both mass and velocity corrections, so the system now takes advantage of the geostrophic balance in the corrections calculated in NCODA, and the model update corrects the scalar fields and the velocities over a $6 \mathrm{~h}$ hindcast. The GOFS system uses the same $6 \mathrm{~h}$ model updating period for HYCOM.

\section{Domain Configuration}

The RELO system was designed to address the requirements of the operational user, who may work under a strict time limit to begin cycling a new domain. Therefore, it provides a simple domain configuration script to assist the user in preparing the text files that control all aspects of domain configuration,
Supporting Databases

The RELO system includes static default databases of tidal water level and transport constituents, river locations and transports, and bathymetry. These default databases provide support for model domain configuration, freshwater discharge, and tidal effects in initial and boundary conditions.

The specification of bathymetry is critical for forecast model performance in shallow water and in regions where the interaction of the external tide, ocean density structure, and bathymetry

\section{ALTHOUGH THE NCODA ANALYSIS DOES NOT ACCOUNT FOR CORRELATED ERROR IN OBSERVATIONS, THERE IS EVIDENCE THAT REPEATED ASSIMILATION OF THE SAME SSHA OBSERVATIONS IN A SERIES OF DAILY GOFS ANALYSES IMPROVES THE FORECAST SKILL FOR THE MESOSCALE FIELD, PARTICULARLY WHEN FEWER ALTIMETERS ARE OPERATING.}

and a set of default analysis and forecast configuration templates. The user need only specify the domain limits in latitude and longitude with a desired horizontal resolution (typically, in meters or kilometers) for the system to define a regular (spherical) grid in longitude-latitude and complete the domain configuration. NCOM and NCODA both support performing analyses and forecasts on more general curvilinear or rotated grids to better match coastline geometry; if the user has already defined such a grid for NCOM using a tool outside the RELO system, the RELO codes support cycling NCOM/NCODA runs on that grid. generates internal tides. In the default domain setup, the NRL two-minute DBDB2 bathymetric database is specified as the source bathymetry, but the user may provide a properly formatted ASCII or netCDF file if desired (e.g., a highresolution gridded bathymetry prepared using classified data sources). The bathymetry processing is performed so as to maintain the coastline shape and mean depths consistent with the model resolution and to match the host model bathymetry at the RELO lateral boundaries. Recent updates to the NRL DBDB2 product include additional sounding data from databases of the National 
Geophysical Data Center (NGDC) and National Geospatial-Intelligence Agency (NGA) (Dong-Shan Ko, NRL, pers. comm., 2013).

The RELO system includes a global tidal constituent database (water level and vector transport), the Oregon State University (OSU) global $0.25^{\circ}$ database (Egbert et al., 1994; Egbert and Erofeeva, 2002). The system is configured so the user may specify an alternate database file in a similar format (e.g., a higher-resolution tide analysis also available from OSU, or one calculated locally using available high-resolution bathymetry).

The constituent database is used during the NCOM configuration to derive height and transport constituents along the lateral boundaries of the outermost nest. These are written to a static NCOM input file and are available if the forecast is configured to run with boundary tides. In that case, the lateral boundary condition information provided from the host model is supplemented with heights and transports calculated during the model integration using the constituent values. Similarly, initial conditions from a non-tidal host model may have tidal heights and transports added to speed the development of realistic tidal flows in the nest. The result is that the RELO nest simulates the barotropic tide throughout the domain, and generates the internal tide where the model bathymetry and stratification interact with the barotropic tide. Lateral boundary conditions created from a nontidal host, however, will not include nonlocal tidally generated internal waves, which may contribute significantly to sound-speed variability in some regions.

Because the NCOM model is hydrostatic, it is not suitable for modeling the development of steep, large-amplitude interior vertical displacements associated with, for example, internal wave solitons. Nonhydrostatic models are more complex and much more expensive to use, so the trade-off is made to balance improving operational capability with available resources. That said, the model at these resolutions has demonstrated skill in simulating the development and propagation of internal bores associated with tidally generated internal waves, and in predicting the location and timing of large-amplitude internal wave packets (Chao et al., 2007), so the representation of the internal tide in the model provides useful guidance on associated ocean and acoustic variability. A recently developed Tidal OpenBoundary Prediction System (Martin et al., 2011) provides the capability to configure and run the OSU Tidal Inversion Software (OTIS) with the NCOM model bathymetry to generate a local, high-resolution tide solution. This results in improved simulation of tides in the regional NCOM domain.

Freshwater inflow is key to proper representation of the thermohaline structure and transports in and around estuaries and coastal river plumes. The default RELO model configuration searches a global river database (Barron and Smedstad, 2002) to identify rivers in the model domain and retrieve their estimated monthly mean discharge rates. The monthly river inflow temperatures are specified using the Generalized Digital Environmental Model Version 4 (GDEM v.4) monthly mean climatology, and the rivers are assumed to be completely fresh. In practice, depending on the coastline geometry represented in a particular RELO instance, the inflow at the source location resolved in the model may be quite brackish, so transport values and the assigned temperatures and salinities may all need to be adjusted; the RELO code includes software to allow these modifications.

\section{OPERATIONAL TESTING}

Before a new RELO domain is declared operational at NAVOCEANO, meaning it may be used to make official forecast products for US Navy users, it first undergoes an evaluation that includes qualitative and quantitative metrics. Qualitative checks confirm that the domain has been properly configured and is generating forecasts that are oceanographically consistent when viewed by an experienced oceanographer. It is also documented that the forecast skill measured against observations is statistically as good as or better than the global model over that domain. Observations utilized have included those from ship-launched XBTs and CTDs, acoustic Doppler current profilers (ADCPs), glider CTDs, and ship set and drift, and data from moorings, tidal stations, drogued drifters, profiling floats, air-launched XBTs, satellite SST and SSHA measurements, and SSH from Deep-ocean Assessment and Reporting of Tsunamis (DART) stations, as well as transport derived from oceanic cable data. The evaluation of each new RELO domain is conducted using daily forecast model runs from a three-month model hindcast. The three-month limitation is imposed partly by the NAVOCEANO operational systems and the limited storage available for keeping time histories of global ocean model, ocean observation, and atmospheric fields available for the hindcast. Because of these storage limitations as well as limited personnel resources, no more than four regions are initialized and evaluated per year.

Each evaluation should show that the 
model properly reproduces vertical and horizontal ocean structures as compared to the published literature and to in situ observations available to NAVOCEANO. Note that NAVOCEANO does not schedule oceanographic surveys to collect data for these evaluations. The evaluations are dependent on what is available through public sources and Navy standard operations. In the case that the domain contains no available in situ observations during the determined time frame of the evaluation, the model is compared to historical in situ observations to ensure the vertical structure is comparable to a climatological reference during the season studied. A variety of statistics against in situ data is then analyzed for the RELO domain and the global model, including means and root mean square error of mixed layer depths and thermocline gradients.

Once the evaluation is complete, an Operational Decision Brief is prepared and presented internally at NAVOCEANO, and a formal decision is made on the operational status of the model. If the model fails its decision brief, it will be reconfigured and the evaluation process will start again; however, it is extremely rare for a RELO domain to fail its decision brief. Usually, problems are identified during the evaluation period, and the model is reconfigured at that time. Once a RELO domain has passed its decision brief and has been declared operational, the output is made available to customers and used in operational forecasting.

\section{EXAMPLE: THE SoCal DOMAIN}

To support US Navy training and exercises and other national interests, a forecast system is maintained for the southern California coast (SoCal). The SoCal domain covers $125^{\circ}-110^{\circ} \mathrm{W}$, $25^{\circ}-40^{\circ} \mathrm{N}$. Figure 2 shows the model bathymetry for the domain. The model bathymetry was processed from internal databases at NAVOCEANO.

The grid spacing is $3.7 \mathrm{~km}$ in the meridional direction and averages $3.1 \mathrm{~km}$ in the zonal, with a range of $2.8-3.3 \mathrm{~km}$. The hybrid vertical grid uses 49 temperature levels from $25 \mathrm{~cm}$ to $5,109 \mathrm{~m}$. In water shallower than the sigma-z interface at $550 \mathrm{~m}$, the vertical grid has 34 terrain-following temperature levels. The lateral boundary tidal constituents were extracted from the default global tide database referenced previously. Nine individual or merged river locations are extracted from the global river database to provide climatological freshwater transports and source temperatures.

Lateral boundary data for NCOM are prepared from real-time GOFS fields, at $3 \mathrm{~h}$ intervals. The surface forcing is prepared from an atmosphere-only COAMPS domain (not shown), configured at $15 \mathrm{~km}$ resolution, in

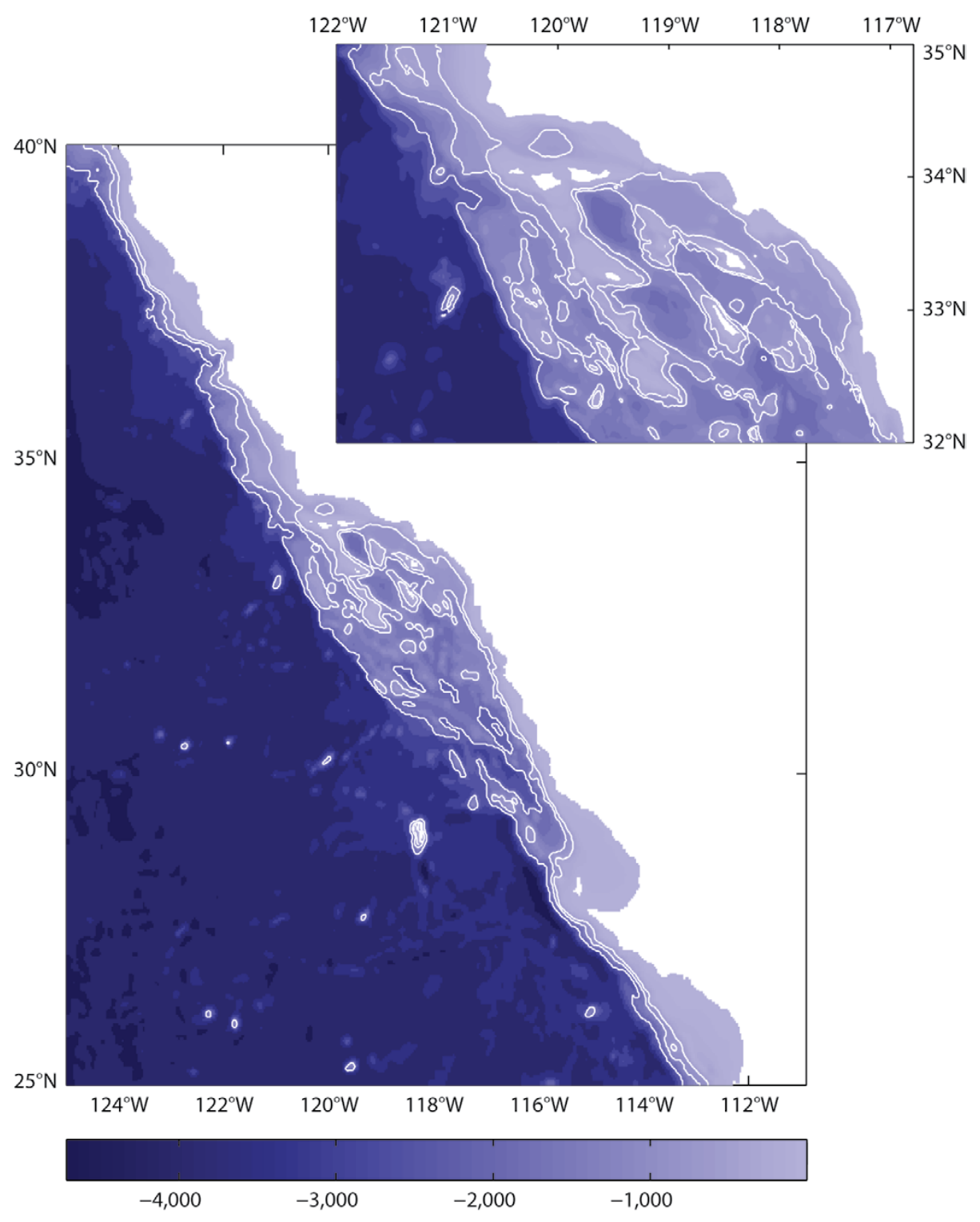

Figure 2. Bathymetry for the southern California coast (SoCal; center) and San Diego (upper right) RELO domains. Contours are overlaid at $500 \mathrm{~m}, 1,000 \mathrm{~m}$, and 2,000 m. 


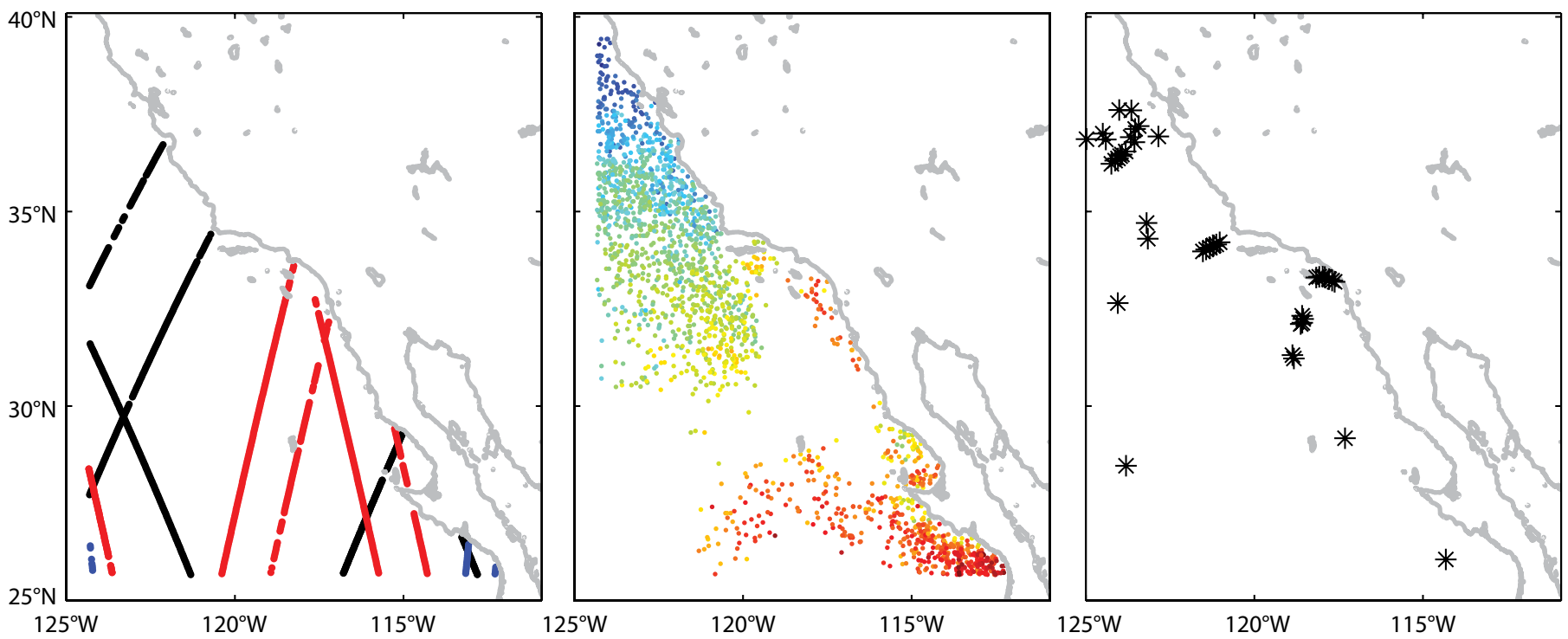

Figure 3. Example observation density for June 15, 2014. For clarity, a larger data window is used for the sea surface height anomaly (SSHA) and profile data. The panels show the positions of $72 \mathrm{~h}$ of altimeter SSHA, $24 \mathrm{~h}$ of sea surface temperature (SST), and $72 \mathrm{~h}$ of profile observations. In the left panel, tracks are shown for the Jason 2 (black), CryoSat 2 (blue), and Altika (red) altimeters.

production at FNMOC. Evaporation and precipitation fluxes are not accounted for in this domain.

Figure 3 compares the relative density of altimeter SSHA, SST, and in situ profile data for an NCODA analysis on
June 15, 2014. Note the limited coverage of in situ observations; although the domain covers areas with significant ship traffic, in situ profile data are still not sufficient to characterize the mesoscale eddy field over the full domain. The
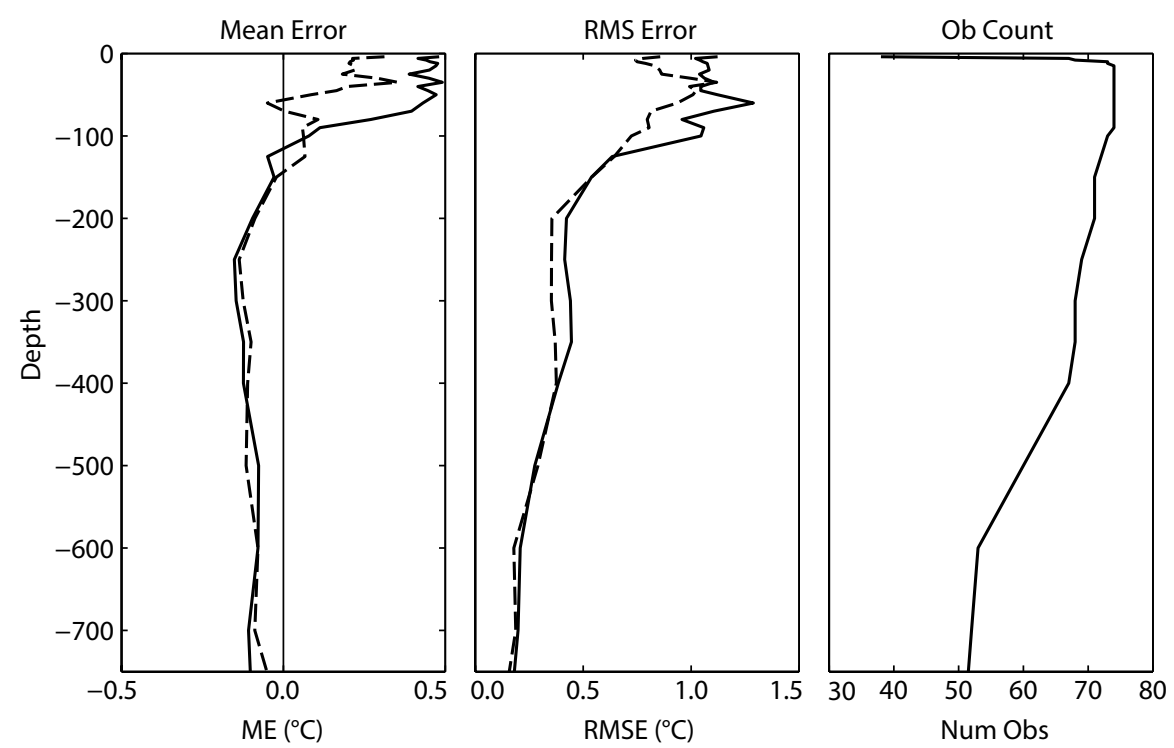

Figure 4. Vertical profiles of the 24-48 h forecast temperature mean error (left), root mean square error (center), and number of observations by depth (right) as measured by in situ profiles from $00 Z$ April 22 to $00 Z$ May 12, 2014, in the SoCal domain, for the $3.7 \mathrm{~km} \mathrm{SoCal}$ RELO domain (solid line) and the Global Ocean Forecast System (GOFS; dashed line).

model will not be sufficiently constrained by the in situ observations alone, and the subsurface structure inferred from the satellite altimeter data is key to keeping the model features on track. However, even a three-day window of SSHA observations is not capable of describing more than the largest features, posing challenging control issues for a model approaching submesoscale resolution.

Results of recent profile comparisons with the SoCal domain and the GOFS system show roughly comparable skill, but better skill near the surface in the GOFS system (Figure 4). While the error statistics for both systems vary from region to region, it is likely that some of the better performance of the GOFS system is related to the data windows and reuse of observations in the analysis described previously. This is currently a topic of investigation.

When higher, subkilometer horizontal resolution is required to predict the shorter length and time scale dynamics of coastal to nearshore domains, a smaller, 
limited-area RELO system is nested in a regional domain. The same process is used to configure the coastal domain, typically using a higher-resolution bathymetric database to capture significant coastal and shelf features.

Because each coastal domain is nested in a regional domain that simulates the external and internal tide, hourly boundary condition data from the regional simulation are used to force the coastal domain, and no additional boundary tide forcing is applied. This presents a challenge for the coastal domain skill in prediction of the external tide, as it depends on the generation and propagation of the external tide across the extent of the regional model. Comparisons in multiple regions (not shown here) have demonstrated that tidal amplitudes and subtidal water level variations (i.e., multiday scales due to winds and coastal waves) compare well with water level gauge measurements, but the coastal domain tide may show phase errors of about $1 \mathrm{~h}$.

The SoCal domain is host to a RELO implementation covering the San Diego area, configured at $555 \mathrm{~m}$ resolution (Figure 2). Figure 5 compares a snapshot of $2 \mathrm{~km}$ coastal radar surface velocity measurements in the Santa Barbara Channel with instantaneous model velocities for the RELO SoCal and San Diego nests and the GOFS system. The San Diego nest shows a better realization of the currents in the channel than the global and regional RELO systems provide. An evaluation of the occurrence of vector difference errors for the three models (Figure 6) shows the San Diego nest has a lower probability of large velocity error, followed by the GOFS system and the SoCal RELO nest.

\section{ONGOING DEVELOPMENT}

An ocean ensemble forecast capability is included in the RELO system (Coelho et al., 2009). The system uses the Ensemble Transform technique (Bishop and Toth, 1999) to cycle the ensemble and maintain the ensemble variance consistent with the analysis error variance estimated from the NCODA analysis. In addition to the Ensemble Transform, a space-time deformation technique based on Gaussian random fields is applied to the atmospheric forcing to simulate error in the atmospheric forecast in the absence of an atmospheric ensemble (Evensen, 2009; Hong and Bishop, 2013). A similar deformation technique may be applied to the global host model fields to account for errors in lateral boundary conditions, and methods for representing sources of error in the model are being explored, including perturbations
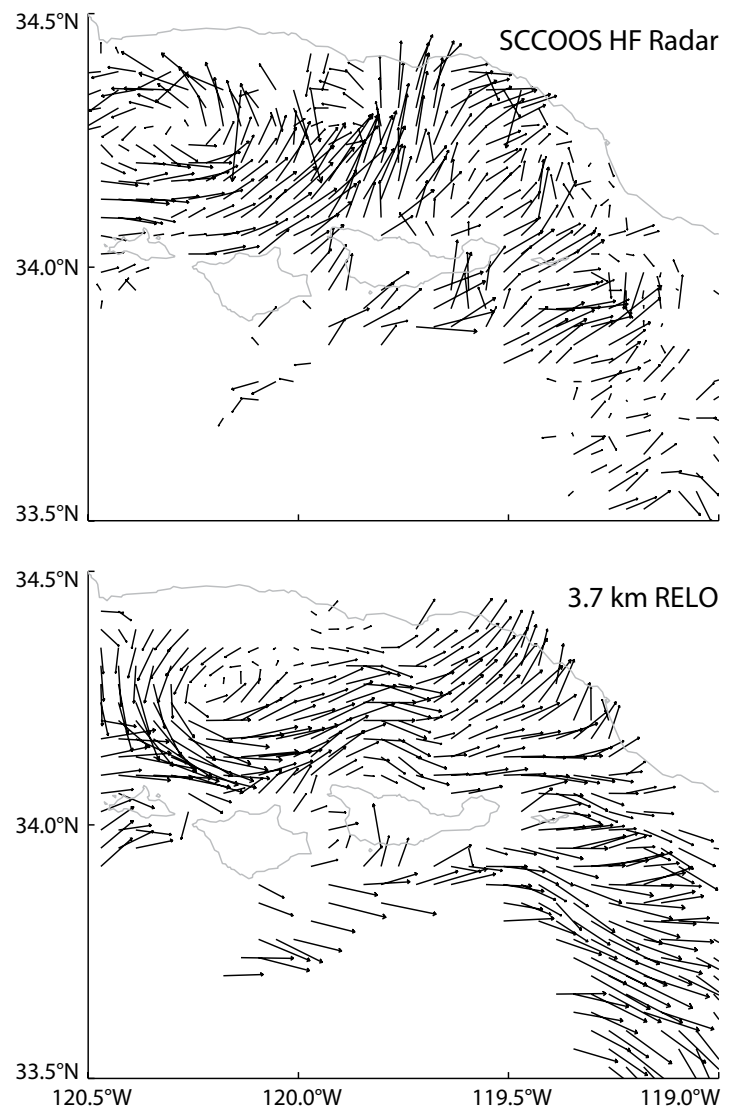
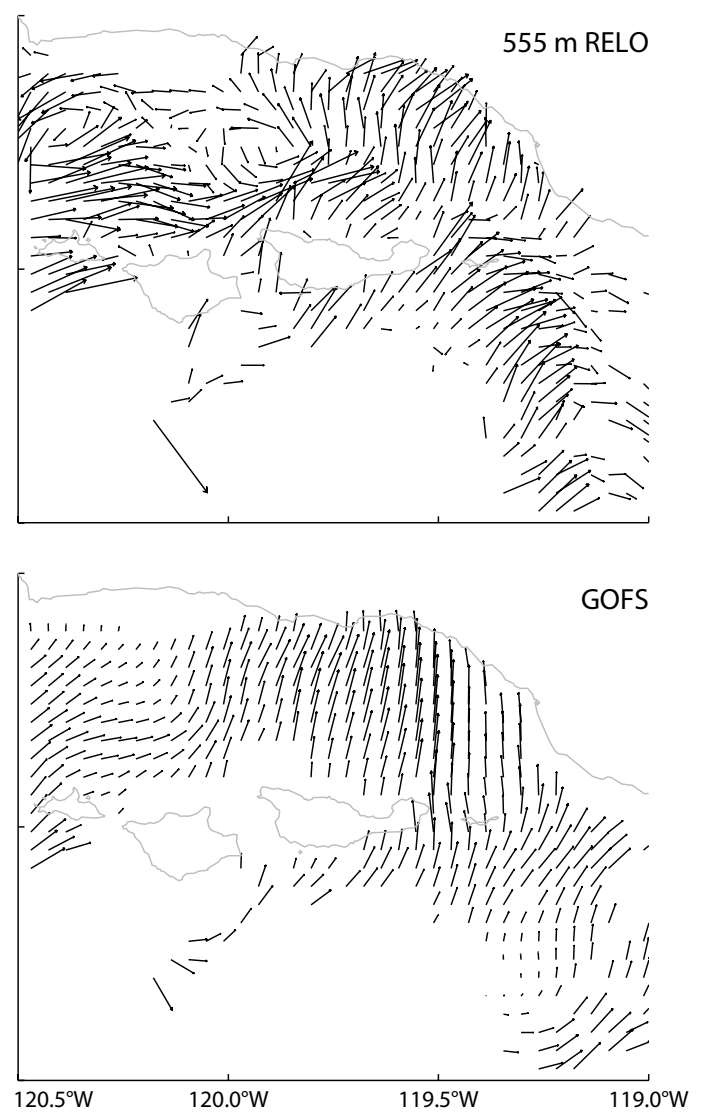

Figure 5. Comparison of radar-measured surface velocity in the Santa Barbara Channel (upper left) with the RELO $555 \mathrm{~m}$ San Diego (upper right), RELO $3.7 \mathrm{~km}$ SoCal (lower left), and GOFS (lower right) model currents for $00 Z$ May 14, 2014. The radar measurements were obtained from the Southern California Coastal Ocean Observing System (SCCOOS) website http://www.sccoos. org/data/hfrnet. 
of the model mixing parameters (Wei et al., 2014) and stochastic forcing techniques (Lermusiaux, 2006).

NRL continues to add capability to COAMPS, including support for ocean-only and coupled ocean-wave modeling (Allard et al., 2014, in this issue). Toward that end, NRL has coordinated development in ocean model configuration, regional-to-coastal nesting, data assimilation, model updating, and post-processing so that the same source codes are used in the RELO and COAMPS systems, and differences in capabilities are due to the added coupling with the atmospheric and wave models. Under one candidate concept of operations, when the full ocean forecast and ensemble capability is transitioned to NAVOCEANO with COAMPS, users will configure coupled air-ocean or airwave-ocean domains on regional scales as well as coupled ocean-wave systems on local coastal domains nested within the regional systems.

The RELO system is also the basis for the first operational transition of the NCOM 4D Variational assimilation (4DVAR) system, developed using the dynamical core of the NCOM forward model. The NCOM 4DVAR is a variational assimilation system based on the indirect representer method; it is described in detail in Ngodock and Carrier (2013).

\section{CONCLUSION}

The NRL relocatable nowcast/forecast system provides a capability for rapidly relocatable ocean forecast modeling and data assimilation for the production of nowcasts and forecasts of three-dimensional ocean temperature, salinity and current structures, and the surface mixed layer; the location of mesoscale features such as eddies, meandering currents, and fronts; and the generation and propagation of external and internal tides. The RELO system is used at NAVOCEANO to support US Navy activity globally, and selected output is made available to the public through cooperation with the US National Oceanic and Atmospheric Administration (e.g., http://ecowatch. ncddc.noaa.gov/amseas).

Continued development work to improve overall RELO system

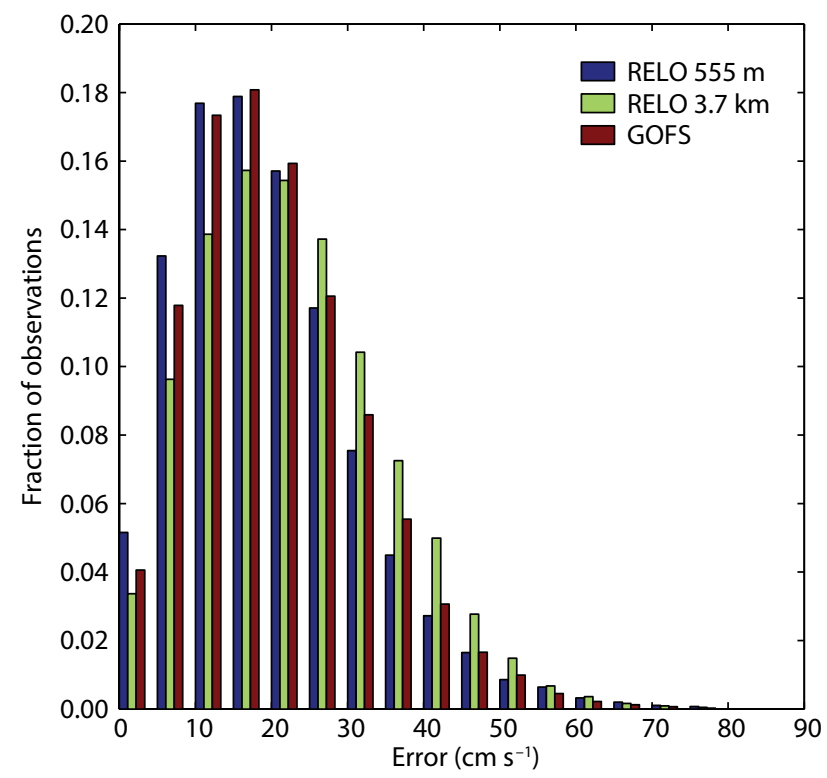

Figure 6. Histogram of the occurrence of vector difference magnitude errors for the RELO 555 m San Diego, RELO 3.7 km SoCal, and GOFS model currents measured against three-hourly radar-measured surface velocity in the Santa Barbara Channel area of Figure 5 for a $60 \mathrm{~h}$ period $00 Z$ May 13 to $12 Z$ May 15 , 2014. The 555 m San Diego nest has a higher likelihood of smaller errors compared to the other models. performance includes the addition of new observing system capabilities, continued improvements to the analysis and forecast components, and enhancements or upgrades to the global modeling system that provides the lateral boundary data. These efforts include a 4DVAR assimilation system, in testing now for transition to operations, and future development of ensemble-based and hybrid ensemble-variational data assimilation approaches with more realistic representation of the error covariances that determine the result of the analysis.

\section{ACKNOWLEDGEMENTS}

The first author's work was funded by the Office of Naval Research under program element $0602435 \mathrm{~N}$ and by the Space and Naval Warfare Systems Command under program element $0603207 \mathrm{~N}$. This paper is NRL contribution number JA/7320-14-2058 and is approved for public release.

\section{REFERENCES}

Allard, R., E. Rogers, P. Martin, T. Jensen, P. Chu, T. Campbell, J. Dykes, T. Smith, J. Choi, and U. Gravois. 2014. The US Navy coupled ocean-wave prediction system. Oceanography 27(3):92-103, http://dx.doi.org/ 10.5670/oceanog.2014.71.

Barron, C.N., A.B. Kara, P.J. Martin, R.C. Rhodes, and L.F. Smedstad. 2006. Formulation, implementation and examination of vertical coordinate choices in the global Navy Coastal Ocean Model (NCOM). Ocean Modelling 11:347-375, http://dx.doi.org/ 10.1016/j.ocemod.2005.01.004.

Barron, C.N., and L.F. Smedstad. 2002. Global river inflow within the navy coastal ocean model. Pp. 1,472-1,479 in Proceedings of the Oceans 2002 MTS/IEEE Conference, Biloxi, MS, October 2002.

Bishop, C.H., and Z. Toth. 1999. Ensemble transformation and adaptive observations. Journal of the Atmospheric Sciences 56:1,748-1,765, http://dx.doi.org/10.1175/1520-0469(1999) 056<1748:ETAAO >2.0.CO;2.

Bloom, S.C., L.L. Takacs, A.M. Da Silva, and D. Ledvina. 1996. Data assimilation using incremental analysis updates. 
Monthly Weather Review 124:1,256-1,271, http://dx.doi.org/10.1175/1520-0493(1996)124 $<1256$ :DAUIAU >2.0.CO;2.

Chao, S.Y., D.S. Ko, R.C. Lien, and P.T. Shaw. 2007. Assessing the west ridge of Luzon Strait as an internal wave mediator. Journal of Oceanography 63:897-911, http://dx.doi.org/ 10.1007/s10872-007-0076-8.

Coelho, E.F., G. Peggion, C. Rowley, G. Jacobs, R. Allard, and E. Rodriguez. 2009. A note on NCOM temperature forecast error calibration using the ensemble transform. Journal of Marine Systems 78:S272-S281, http://dx.doi.org/10.1016/j.jmarsys.2009.01.028.

Cummings, J.A., and O.M. Smedstad. 2013. Variational data assimilation for the global ocean. Pp. 303-343 in Data Assimilation for Atmospheric, Oceanic and Hydrologic Applications, vol. II. S.K. Park and L. Xu, eds, Springer Berlin/Heidelberg.

De Mey, P., P. Craig, F. Davidson, C.A. Edwards, Y. Ishikawa, J.C. Kindle, R. Proctor, K.R. Thompson, J. Zhu, and the GODAE Coastal and Shelf Seas Working Group (CSSWG) Community. 2009. Applications in coastal modeling and forecasting. Oceanography 22(3):198-205, http://dx.doi.org/10.5670/oceanog.2009.79.

Egbert, G.D., A.F. Bennett, and M.G.G. Foreman. 1994. TOPEX/Poseidon tides estimated using a global inverse model. Journal of Geophysical Research: Oceans 99:24,821-24,852, http://dx.doi.org/10.1029/94JC01894.

Egbert, G.D., and S.Y. Erofeeva. 2002. Efficient inverse modeling of barotropic ocean tides. Journal of Atmospheric and Oceanic Technology 19:183-204, http://dx.doi.org/10.1175/1520-0426(2002) 019<0183:EIMOBO>2.0.CO;2.

Evensen, G. 2009. Data Assimilation: The Ensemble Kalman Filter, 2nd ed. Springer, New York, $307 \mathrm{pp}$.

Fisher, M., and E. Andersson. 2001. Developments in $4 D$-Var and Kalman Filtering. Technical Memorandum 347, European Center for Medium Range Weather Forecasts, Reading, Berks, UK, 36 pp.

Fox, D.N., W.J. Teague, C.N. Barron, M.R. Carnes, and C.M. Lee. 2002. The Modular Ocean Data Analysis System (MODAS). Journal of Atmospheric and Oceanic Technology 19:240-252, http://dx.doi.org/ 10.1175/1520-0426(2002)019<0240: TMODAS $>2.0 . C O ; 2$.

Hodur, R.M., X. Hong, J.D. Doyle, J. Pullen, J. Cummings, P. Martin, and M.A. Rennick. 2002. The Coupled Ocean/Atmosphere Mesoscale Prediction System (COAMPS). Oceanography 15(1):88-98, http://dx.doi.org/ 10.5670/oceanog.2002.39.

Hogan, T.F., M. Liu, J.A. Ridout, M.S. Peng, T.R. Whitcomb, B.C. Ruston, C.A. Reynolds, S.D. Eckermann, J.R. Moskaitis, N.L. Baker, and others. 2014. The Navy Global Environmental Model. Oceanography 27(3):116-125, http://dx.doi.org/10.5670/oceanog.2014.73.
Hong, X., and C. Bishop. 2013. Ocean ensemble forecasting and adaptive sampling. Pp. 391-409 in Data Assimilation for Atmospheric, Oceanic and Hydrologic Applications, vol. II. S.K. Park and L. Xu, eds, Springer Berlin/Heidelberg.

Horton, C., M. Clifford, J. Schmitz, and L.H. Kantha. 1997. A real-time oceanographic nowcast/forecast system for the Mediterranean Sea. Journal of Geophysical Research 102:25,123-25,156, http://dx.doi.org/10.1029/97JC00533.

Kara, A.B., H.E. Hurlburt, and A.J. Wallcraft. 2005. Stability-dependent exchange coefficients for air-sea fluxes. Journal of Atmospheric and Oceanic Technology 22:1,080-1,094, http://dx.doi.org/10.1175/JTECH1747.1.

Large, W.B., and S. Pond. 1981. Open ocean momentum flux measurements in moderate to strong winds. Journal of Physical Oceanography 11:324-336, http://dx.doi.org/10.1175/1520-0485(1981) $011<0324$ :OOMFMI $>2.0$. CO;2.

Lermusiaux, P.F.J. 2006. Uncertainty estimation and prediction for interdisciplinary ocean dynamics. Journal of Computational Physics 217:176-199, http://dx.doi.org/10.1016/j.jcp.2006.02.010.

Mainelli, M., M. DeMaria, L. Shay, and G. Goni. 2008. Application of oceanic heat content estimation to operational forecasting of recent Atlantic category 5 hurricanes. Weather and Forecasting 23:3-16, http://dx.doi.org/ 10.1175/2007WAF2006111.1.

Martin, P.J., S.R. Smith, G.M. Dawson, P.G. Posey, and E.D. Zaron. 2011. Validation test report for the Tidal Open-boundary Prediction System (TOPS). Memorandum Report NRL/ MR/7320-11-9296. Naval Research Laboratory, Washington, DC, $66 \mathrm{pp}$.

Metzger, E.J., O.M. Smedstad, P.G. Thoppil, H.E. Hurlburt, J.A. Cummings, A.J. Wallcraft, L. Zamudio, D.S. Franklin, P.G. Posey, M.W. Phelps, and others. 2014. US Navy operational global ocean and Arctic ice prediction systems. Oceanography 27(3):32-43, http://dx.doi.org/10.5670/oceanog.2014.66.

Ngodock, H.E., and M.J. Carrier. 2013. A weak constraint $4 \mathrm{D}$-Var assimilation system for the Navy Coastal Ocean Model using the representer method. Pp. 367-390 in Data Assimilation for Atmospheric, Oceanic and Hydrologic Applications, vol. II. S.K. Park and L. Xu, eds, Springer Berlin/Heidelberg.

Wei, M., C. Rowley, P. Martin, C.N. Barron, and G. Jacobs. 2014. The US Navy's RELO ensemble prediction system and its performance in the Gulf of Mexico. Quarterly Journal of the Royal Meteorological Society 140:1,120-1,149, http://dx.doi.org/10.1002/qj.2199.

Willis, J.K., D. Roemmich, and B. Cornuelle. 2003. Combining altimetric height with broadscale profile data to estimate steric height, heat storage, subsurface temperature, and sea-surface temperature variability. Journal of Geophysical Research 108, 3292, http://dx.doi.org/10.1029/2002JC001755. 